\title{
Las cenizas de El marinero: un polígono de lados infinitos
}

NICOLÁS BARBOSA

Nicolás Barbosa es licenciado en Literatura y Letras por la Facultad de Artes y Humanidades de la Universidad de los Andes (Bogotá, Colombia). Es responsable por ediciones bilingües (portugués-español) de la obra de Fernando Pessoa, designadamente O Banqueiro Anarchista (2013, Tragaluz) y O Marinheiro (2015, Tragaluz). Tradujo al español una antología de la obra de José de Almada-Negreiros (2016, Ediciones Uniandes), tres libros de Afonso Cruz (Tragaluz, Panamericana), y, con Jerónimo Pizarro, una antología de poesía portuguesa (2015, Pre-Textos), además de otros autores como Maria do Rosário Pedreira, José Tolentino Mendonça, Valter Hugo Mãe, José Luís Peixoto, Manuel António Pina y Raul Brandão. Colabora regularmente con artículos sobre literatura portuguesa en la revista digital Pessoa Plural e integra el equipo de Fausto: uma existência digital, que prepara una edición digital de esta obra inacabada de Fernando Pessoa.

Na sua proposta de «teatro estático» e na única obra de teatro que publicou em vida, o Marinheiro, Fernando Pessoa cria um teatro paradoxalmente cinzelado que se constrói sobre a ideia negativa de uma privação criadora; ou seja, trata-se de um teatro de autodestruição. A dupla metáfora entre a escultura e a linguística revela-se apropriada pois uma das maiores criações teatrais de Pessoa é precisamente um homem esculpido a partir de palavras. A personagem do marinheiro, criação central desta peça, é ao mesmo tempo o maior enigma da história e a janela para as possibilidades metafóricas da encenação.

FERNANDO PESSOA / O MARINHEIRO / ENCENAC̣ÃO / LINGUÍSTICA / SIMBOLISMO

Una de las similitudes entre el arte de la escultura y la lexicografía es la estrategia inicial para dar con el objeto creado, que en el primer caso es la obra esculpida, y en el segundo, la definición. Uno y otro parten de una concepción negativa de la materia. Mientras que la obra esculpida necesita de un molde inverso -que corresponde al negativo del modelo inicial, idéntico en volumen a la obra final, y en cuyo vacío se vierte el material cuya forma reflejará los contornos positivos-, cierta metodología en la lingüística recurre a la definición de los conceptos mediante la enumeración de lo que éstos no son. Que el acto de la creación se dé a partir de la remoción -ya sea del metal o de las acepciones- no parece ser un patrón lejano para el portugués Fernando Pessoa, sobre todo cuando se trata de su concepción acerca del teatro. Tanto su propuesta de "teatro 
estático" como su única obra teatral finalizada y publicada en vida, El marinero, permiten afirmar que el teatro cincelado de Fernando Pessoa se erige, justamente, en la idea negativa de una remoción creadora: un teatro de la autodestrucción.

Es pertinente la doble metáfora con la escultura y la lingüística porque una de las mayores creaciones teatrales de Pessoa es precisamente un hombre esculpido a partir de las palabras. El personaje del marinero, la creación central de esta obra de teatro, es al mismo tiempo la mayor cifra de la historia. Más allá del título, poco sabemos sobre él antes del final, como aparición en el sueño relatado de una veladora. $Y$ ni siquiera cuando es nombrado por otro lo vemos o lo oímos, pues sólo emerge bajo la forma de un relato ajeno, y el hombre nunca se revela ni se expresa autónomamente. Entre tanto, llegamos a él sin realmente alcanzarlo, pues hay que atravesar una sucesión de capas indefinidas que lo van construyendo en palabras y a la vez lo van desdibujando en la imagen: el discurso de la veladora, su sueño, y lo que parece ser un sueño relatado dentro de un sueño. En él, entonces, convergen todos los misterios de la obra así como el método ambiguo de creación. Hablar de él es negarle un discurso propio a la vez que se le despoja de toda materialidad. Como enunciado que nombra un vacío, el anti-título de esta obra representa la primera en una serie de ideas en negativo del teatro y la realidad.

Tras el título, surge una problemática autodenominación de esta obra: "drama estático en un cuadro". Ni en su sentido aristotélico ni coloquial la obra demuestra ser un drama de verdad. De hecho, no podría siquiera ser un "drama estático", si partimos de la idea de "acción" que Aristóteles asocia al "drama" en su Poética, y por lo tanto no estamos sino ante un ejemplo típicamente pessoano del oxímoron (que, a su vez, nos recuerda a la figura del lingüísticamente imposible banquero anarquista que el autor habría de crear poco después). Por otro lado, la obra está claveteada de momentos que más que un "drama" parecen no ser sino una burla descarada del género teatral. He aquí un teatro que se dice dramático aunque en él nada avance ni suceda, con personajes que no sólo hablan sin saber por qué sino que además lo dicen en voz alta, cual parodiadores del tramoyista que los dirige, cual actores que al hacer el papel de actores ponen en duda el guion mismo que profieren. He aquí una obra disfrazada de obra, pero que diálogo tras diálogo no parece sino querer destruir toda noción del teatro 
$\mathrm{y}$, por consiguiente, fracturar su propia máscara, esto es, irse cincelando hasta dar con su esencia imposible de "teatro estático".

Al cuestionar sus propias palabras, las veladoras en El marinero quiebran el límite entre el parlamento y la improvisación, y en un eco a los personajes híperconscientes de Seis personajes en busca de un autor, de Luigi Pirandello, estas mujeres buscan infructuosamente al ente creador que las obliga a hablar-el guionista-, el cual, a su vez, se entremezcla con el objeto creado del cual ellas hablan -el marinero-. Como una especie de dios en negativo (es decir, un creador que a su vez es creado), el marinero funge simultáneamente como el motor que impulsa el desarrollo de los parlamentos y el objeto deseado de este mismo impulso. Con el anhelo de llegar a él es que las mujeres hablan y la obra avanza en medio de su escasa acción; sin embargo, él también es el contenido de los diálogos. En esa búsqueda contradictoria de un marinero elusivo, las veladoras sabotean su propio objetivo: mantienen un discurso fragmentado, incompleto, carente de toda autonomía y que parece sostenerse sólo cuando unas se complementan a las otras. Estamos, entonces, frente a personajes supuestamente teatrales que parecen construidos para nunca ser representados: el primero, un protagonista que nunca se visibiliza; y las demás, unas mujeres indistinguibles entre sí, símil de una trinidad insostenible en la realidad, y de cuya existencia ni siquiera tenemos certeza. Así, estamos frente a un escenario que se difumina a medida que progresa, y nos convertimos en el público de un sucedáneo de una escena real.

Más adelante en la obra, con la revelación de que posiblemente sea el marinero quien las esté soñando a ellas y no al revés, no sólo el propósito de este escenario desaparece sino también la función del espectador/lector. Este teatro de planos múltiples (y no de un único cuadro, como sugiere falsamente el subtítulo), parece desdibujar también al lector. Éste ignora si su lugar como espectador ha sido desplazado, si para saberse público no debería más bien estar en ese otro escenario ilocalizable donde se lleva a cabo la escena de un náufrago marinero. Entre tanto, su existencia también es incierta, pues al ser incapaz de pertenecer al potencial mundo real del marinero que sueña a las veladoras, el lector es, por extensión, una entidad que hace parte del sueño.

El espacio físico en el que se dice que toma lugar la obra también está cargado de transgresiones que ponen en duda la viabilidad de este teatro. El "cuadro único" de la historia sin marinero de 
El marinero sucede en una habitación circular, un torreón o cubo (como se le llama en la arquitectura militar) que transmite la idea de un escenario circular e impenetrable. Resulta revelador que el teatro de Pessoa sea posible sólo en tanto que esté delimitado por un círculo y encerrado entre un cilindro de piedras que bloquean toda visibilidad. Sólo como un escenario imposible -como un teatro no-teatro- es que existe el cuadro único de El marinero. En efecto, el escenario es imposible dado que, al igual que toda circunferencia, se constituye como un polígono de lados infinitos que, al no tener vértices, no tiene principio ni fin. Es imposible porque destruye la idea de espectador y, al estar desprovisto de público, deja por definición de ser un escenario. El espectador no tiene más remedio que estar atrapado dentro del círculo del territorio de las veladoras, cumpliendo el doble rol de público y actor, o ser un observador externo al otro lado de la única salida que existe, la ventana, un territorio inasequible para el público y para las veladoras mismas, y el cual, además, representa el espacio del marinero.

Emerge, entonces, la verdad ineludible de que estamos ante un teatro que, en su encierro, se consume a sí mismo. El marinero parece ser el único espectador posible en este teatro, pues sólo él está del lado que permitiría poder ver el escenario de las veladoras, a pesar de que ellas no lo puedan ver a él. Él es, además, el personaje central (aunque desplazado del centro de toda acción y por ende inalcanzable), a la vez objeto del discurso y dios creador que da vida a las veladoras que lo enuncian. Como punto de fuga y a la vez punto de convergencia, el marinero es la metáfora por excelencia del círculo que no lo encierra a él pero sí a quienes relatan su historia. Él es tanto el inicio como el fin y, por consiguiente, es un punto en la circunferencia imposible de rastrear justamente porque es, en sí mismo, la circunferencia entera.

Que Pessoa abra su obra de teatro con la referencia euclidiana de la habitación (su forma, una circunferencia; sus ocupantes, puntos que forman el centro y los radios) resulta enigmático debido a que el círculo constituye una de las formas más elusivas a la lexicografía. Su significado parece traspasar los límites de su definición, y el consabido símil poligonal ("un círculo es un polígono de lados infinitos") es falso, pues las circunferencias nunca serán sucesiones de rectas por más cortas que éstas lleguen a ser. Como noción para la cual el lenguaje resulta insuficiente, el círculo-que aquí representa el límite de una propuesta teatral y se 
encarna en la figura del marinero- es metáfora de lo que parece ser el objetivo ulterior en gran parte de la obra de Fernando Pessoa: destruir las palabras y los significados (incluido aquí el género teatral) para erigir un lenguaje imposible.

El patrón pessoano de construir a partir de la destrucción se refleja en el lugar literario que ocupa El marinero, como bisagra de las tradiciones que sucede y antecede. Varios estudiosos han manifestado lo paradójico que resulta este texto dado que representa el germen de las nuevas corrientes del siglo $\mathrm{xx}$, a la vez que retoma algunas tradiciones literarias que lo anteceden para, en parte, destruirlas. Igualmente, el proceso de creación de este texto (como ocurrió con muchas otras creaciones pessoanas) constituyó una interminable tensión entre escritura y obliteración, entre moldeado y erosión. El marinero atravesó procesos de reedición que, de acuerdo a testimonios de Pessoa mismo, no parecen haber redundado en una versión explícitamente identificada como la final.

En una carta a Armando Côrtes-Rodrigues del 4 de marzo de 1915, por ejemplo, Pessoa afirma que la versión de ese año es diferente a la supuesta versión inicial de 1913 (este año de escritura lo proporciona el propio Pessoa, y por lo tanto puede tratarse de una fecha ficticia creada a posteriori): "O meu drama estático 'O Marinheiro' está bastante alterado e aperfeiçoado; a forma que v. conhece é apenas a primeira e rudimentar. $O$ final, especialmente, está muito melhor. Não ficou, talvez, uma coisa grande, como eu entendo as coisas grandes; mas não é coisa de que eu me envergonhe, nem-creio- me venha a envergonhar" (Pessoa, 1985: 58). Y casi dos décadas después, en una carta a João Gaspar Simões, quien le había propuesto publicar algunos de sus textos más viejos, Pessoa se rehusó a publicar la obra por considerarla inacabada: "O Marinheiro está sujeito a emendas: peço que, por enquanto, se abstenham de pensar nele. Se quiserem, poderei, feitas as emendas, dizer quais são" (Pessoa, 1998: 115).

Con base en los eventos ocurridos en torno a su difícil publicación, es válido afirmar que El marinero sí instituyó una amenaza contra las tradiciones vigentes en Portugal a comienzos de siglo. A pesar de que Pessoa ya tenía una relación con la revista A Águia, la cual en parte se basaba en un interés común por el 
sebastianismo y el saudosismo, en 1913 esta revista rechazó publicar El marinero. Lo que vino después fue una de las grandes rupturas literarias en Portugal, y en efecto Lisboa y Oporto tomaron caminos distintos. Pessoa lograría publicar su obra tan sólo dos años después en Orpheu n. ${ }^{\circ}$, la revista que luego habría de adquirir un estatus fundacional como cuna del modernismo portugués.

Para comprender mejor la compleja amalgama de tradiciones que habita El marinero es útil remitirse a otra carta que da cuenta de los varios intentos de publicación. En esta misiva de 1914 enviada a Álvaro Pinto, Pessoa reniega de su ruptura con A Águia y a la vez asemeja El marinero a En la floresta del enajenamiento, un texto que había publicado en julio de 1913, justamente en A Águia, y cuya cercanía con la obra teatral y su temático del sueño es innegable, como se ve en el siguiente fragmento: "Sei que despertei e que ainda durmo. O meu corpo antigo, moído de eu viver diz-me que é muito cedo ainda... Sinto-me febril de longe. Peso-me, não sei porquê...” (Pessoa, 2013: 58). Que la obra teatral haya sido tan similar a un texto que ya había sido aceptado por A Águia y al mismo tiempo tan disímil como para haber sido rechazado refleja la cantidad de máscaras que envuelven esta obra teatral.

Varios teóricos también han señalado los vínculos con el simbolismo, movimiento francés del siglo XIX. La relación entre El marinero y esta corriente es igualmente rica en paradojas, pues Pessoa renegó de los simbolistas al mismo tiempo que se asoció - por voluntad propia- a ellos. Mientras los catalogaba como escritores de lo que consideraba "uma fase decadente do Romantismo" (en Rebello 18), Pessoa también trazó un paralelo entre su obra teatral y la obra de Maurice Maeterlinck. Y a la vez que el portugués se ve reflejado en el simbolismo del belga, también afirma que El marinero es una obra "remota" dentro de las tradiciones literarias por lograr llevar los elementos simbolistas a un nivel superior al de Maeterlinck: "A melhor nebulosidade e subtileza de Maeterlinck é grosseira e carnal em comparação" (Pessoa, 1966: 148). Es decir, se vale de ciertos preceptos simbolistas -a saber, un drama indiferente a lo externo, indefinido en el tiempo y el espacio, con planos de realidades que se sobreponen y se borran entre sípara destruirlos pero más adelante reformularlos.

Fiel a su patrón de habitar varias corrientes a la vez, Pessoa también insertó El marinero dentro del sensacionismo, surgido en 1915 y 1916, y bajo la identidad del compilador ficticio Sher 
Henay incluyó la obra dentro del proyecto de una antología sensacionista en inglés. No resulta difícil ver cómo la pieza teatral logra corresponderse con esta corriente, sobre todo al analizar los textos en que Pessoa define el sensacionismo, como por ejemplo la máxima "Sentir es crear. Actuar es solo destruir" (Pessoa, 2009: 179). En esta corriente, a su vez, convergen movimientos tradicionalmente antagónicos entre sí, y por lo tanto representa la conjunción de oxímoros de El marinero. A la vez que se preocupaba por un "análise profunda dos estados de alma", el sensacionismo también entremezcló elementos introducidos por los futuristas, como Walt Whitman, y censuró aquello que Pessoa definió como una "exclusiva preocupação do vago" (Pessoa, 1966: 188). Por lo tanto, tampoco debe sorprender que la obra teatral haya sido finalmente publicada en las páginas de Orpheu, una revista que también se constituye como bisagra entre simbolismo y modernismo, con textos tan disímiles como Frisos, de José de Almada Negreiros, y la futurista Oda triunfal.

Críticos como Teresa Rita Lopes y Antonio Tabucchi han coincidido en afirmar la ambigua relación que existe entre El marinero y las corrientes que la anteceden. Lopes, por ejemplo, menciona la obra Los ciegos (1890), de Maeterlinck, en la cual también se aborda una tragedia interior, con protagonistas semirreales, estáticos y encerrados en un espacio indeterminado. Pero a pesar de que las veladoras de Pessoa son un espejo de estas decisiones puramente simbolistas, afirma Lopes, ellas también contravienen imágenes propias del movimiento. En Pessoa, la noción de oscuridad, por ejemplo, que para los simbolistas era asociada a lo macabro, es el terreno fértil de la creación: el sueño que relatan las veladoras -es decir, la creación paulatina del marinero- ocurre durante la noche. Por su parte, Tabucchi agrega que además de sus ecos simbolistas, El marinero revela una clara correspondencia con Shakespeare, quien en su obra La tempestad también se pregunta por esa tenue división que hay entre la vida real y los sueños: "Estamos tejidos / de idéntica tela que los sueños, y nuestra corta vida / se cierra con un sueño" (acto IV, escena 1, versos 156 a 158).

Del otro lado, también hay hilos que vinculan el teatro de Pessoa con obras posteriores como Esperando a Godot, de Samuel Beckett, o la ya mencionada obra de Pirandello, Seis personajes en busca de un autor. En Beckett vemos personajes que también permanecen 
inmóviles, esperando a un sujeto que nunca se revela ni llega. Incluso la indefinición de los personajes en Godot se asemeja a la vaguedad de las veladoras de Pessoa, como entes que parecen no ser individuos reales sino personajes que se funden entre sí. De esto último, además, surge una de las propuestas que más reivindican el teatro pessoano como cimiento de la totalidad de su legado literario, pues algunos críticos han apuntado que es justamente en las veladoras donde se gesta el eterno dilema de la pluralidad y, en otras palabras, una versión (preliminar) del heteronimismo.

Lo anterior demuestra que esta obra teatral, en cuanto bisagra de tradiciones literarias y plétora de corrientes similares y antagónicas, no es sino una expresión de la imposibilidad lingüística. Que encaje y a la vez se salga de los límites de las definiciones -y de las clasificaciones literarias-apunta a que, no sólo en su concepción estructural y sus posibilidades metafóricas sino también en su lugar histórico, estamos frente a un círculo imposible. El marinero, antecesora y predecesora, partidaria y enemiga de sí misma, es justamente el punto inicial de un círculo: presente pero sin rastro, único pero potencialmente todos los puntos de la circunferencia, e inicial a pesar de que bien podría ser el punto final. Dicha imposibilidad de discernir entre fin e inicio es justamente aquello que se revela en la naturaleza cifrada del personaje central, un hombre muerto entre un mar de ensueño en el que, a la vez, parece ser el único sobreviviente.

\title{
Abat-jour $^{1}$
}

A lampada accesa

(Outrem a accendeu)

Baixa uma belleza

Sobre o chão que é meu.

\author{
No quarto deserto \\ Salvo o meu sonhar, \\ Faz no chão incerto \\ Um círculo a ondear.
}


E entre a sombra e a luz

Que oscilla no chão

Meu sonho conduz

Minha inattenção.

Bem sei... Era dia

E longe de aqui...

Quanto me sorria

O que nunca vi!

E no quarto silente

Com a luz a ondear

Deixei vagamente

Até de sonhar...

\section{REFERENCIAS BIBLIOGRÁFICAS}

LOPEs, Teresa Rita (2004), Fernando Pessoa et le drame symboliste: Héritage et Création, París, Éditions de la Différence, pp. 183-208 (primera ed. 1977).

PESSOA, Fernando (1966), Páginas Íntimas e de Auto-Interpretação, edición y prólogo de Georg Rudolf Lind y Jacinto do Prado Coelho, Lisboa, Ática.

-- (1985), Cartas de Fernando Pessoa a Armando Côrte-Rodrigues, introducción de Joel Serrão, Lisboa, Livros Horizonte.

-- (1988), Cartas entre Fernando Pessoa e os directores da Presença, edición y estudio de Enrico Martines, Lisboa, Imprensa Nacional-Casa da Moeda.

-- (2009), Sensacionismo e outros Ismos, edición de Jerónimo Pizarro, Lisboa, Imprensa Nacional-Casa da Moeda.

-- (2013), Livro do Desassossego, edición de Jerónimo Pizarro, Lisboa, Tinta-da-china.

REBELLO, Luiz Francisco (1979), O Teatro Simbolista e Modernista (189o-1939), Lisboa, Instituto de Cultura Portuguesa.

TABUCCHI, Antonio (1998), Un baúl lleno de gente, traducción de Pedro Luis Ladrón de Guevara Mellado, Buenos Aires, Temas. 